\title{
Long Noncoding RNA: Significance and Potential in Skin Biology
}

\author{
Derrick C. Wan ${ }^{1}$ and Kevin C. Wang ${ }^{1,2,3}$ \\ ${ }^{1}$ Department of Surgery, Stanford University School of Medicine, Stanford, California 94305 \\ ${ }^{2}$ Department of Dermatology Stanford University School of Medicine, Stanford, California 94305 \\ ${ }^{3}$ Program in Epithelial Biology, Stanford University School of Medicine, Stanford, California 94305 \\ Correspondence: kevwang@stanford.edu
}

Over the past few years, advances in genome analyses have identified an emerging class of noncoding RNAs that play critical roles in the regulation of gene expression and epigenetic reprogramming. Given their transcriptional pervasiveness, the potential for these intriguing macromolecules to integrate a myriad of external cellular cues with nuclear responses has become increasingly apparent. Recent studies have implicated noncoding RNAs in epidermal development and keratinocyte differentiation, but the complexity of multilevel regulation of transcriptional programs involved in these processes remains ill defined. In this review, we discuss the relevance of noncoding RNA in normal skin development, their involvement in cutaneous malignancies, and their role in the regulation of adult stem-cell maintenance in stratified epithelial tissues. Furthermore, we provide additional examples highlighting the ubiquity of noncoding RNAs in diverse human diseases.

\section{AN EMBARRASSMENT OF RICHES?}

For most of the past few decades, the focus Fof molecular biologists has centered around protein-coding genes in the genome, although they comprised $<2 \%$ of the human genome sequence (Lander et al. 2001; Venter et al. 2001). RNA was often regarded as a simple intermediary between DNA and protein. More recently, with the advent of large-scale analyses of mammalian transcriptomes (Claverie 2005; Kapranov et al. 2007; Mercer et al. 2009), scientists have come to appreciate a new class of transcripts, noncoding RNAs (ncRNAs), that are pervasively transcribed in the genome. Why are they so pervasive and do they have function? Long thought to be transcriptional "noise," these RNAs have now been increasingly implicated to play functional roles in gene regulation (Wang and Chang 2011). In contrast to other better characterized, small ncRNAs such as microRNAs (miRNAs) and Piwi-interacting RNAs, which are highly conserved and involved in transcriptional and posttranscriptional gene silencing through specific base pairing with their targets (He and Hannon 2004; Mendell 2005; Aravin et al. 2007; Brennecke et al. 2007), long noncoding RNAs (lncRNAs), which are arbitrarily defined as transcribed RNA molecules $>200$ nucleotides in length, are poorly con-

Editors: Anthony E. Oro and Fiona M. Watt

Additional Perspectives on The Skin and Its Diseases available at www.perspectivesinmedicine.org

Copyright (C) 2014 Cold Spring Harbor Laboratory Press; all rights reserved; doi: 10.1101/cshperspect.a015404

Cite this article as Cold Spring Harb Perspect Med 2014;4:a015404 
D.C. Wan and K.C. Wang

served and regulate gene expression by diverse mechanisms that are not yet fully understood (Bernstein and Allis 2005; Bracken and Helin 2009; Faghihi and Wahlestedt 2009; Mercer et al. 2009; Whitehead et al. 2009; Wilusz et al. 2009; Wang and Chang 2011).

Although only a handful of functional lncRNAs have been well characterized to date, recent work suggests that lncRNAs are at the heart of diverse biological processes such as imprinting (Nagano and Fraser 2009), enhancer func- 2010a), X-chromosome inactivation (Lee 2009), and chromatin structure (Rinn et al. 2007; Wang et al. 2011). They also appear to be critical for normal development and have been found to be dysregulated in many diseases such as cancer (Fig. 1) (Ørom et al. 2010b).

Given the large number of lncRNAs whose functions are now only beginning to be elucidated, there is clear potential for widespread regulation and/or modulation of gene expression. Furthermore, it is easy to imagine lncRNAs playing major roles in determining the epige-

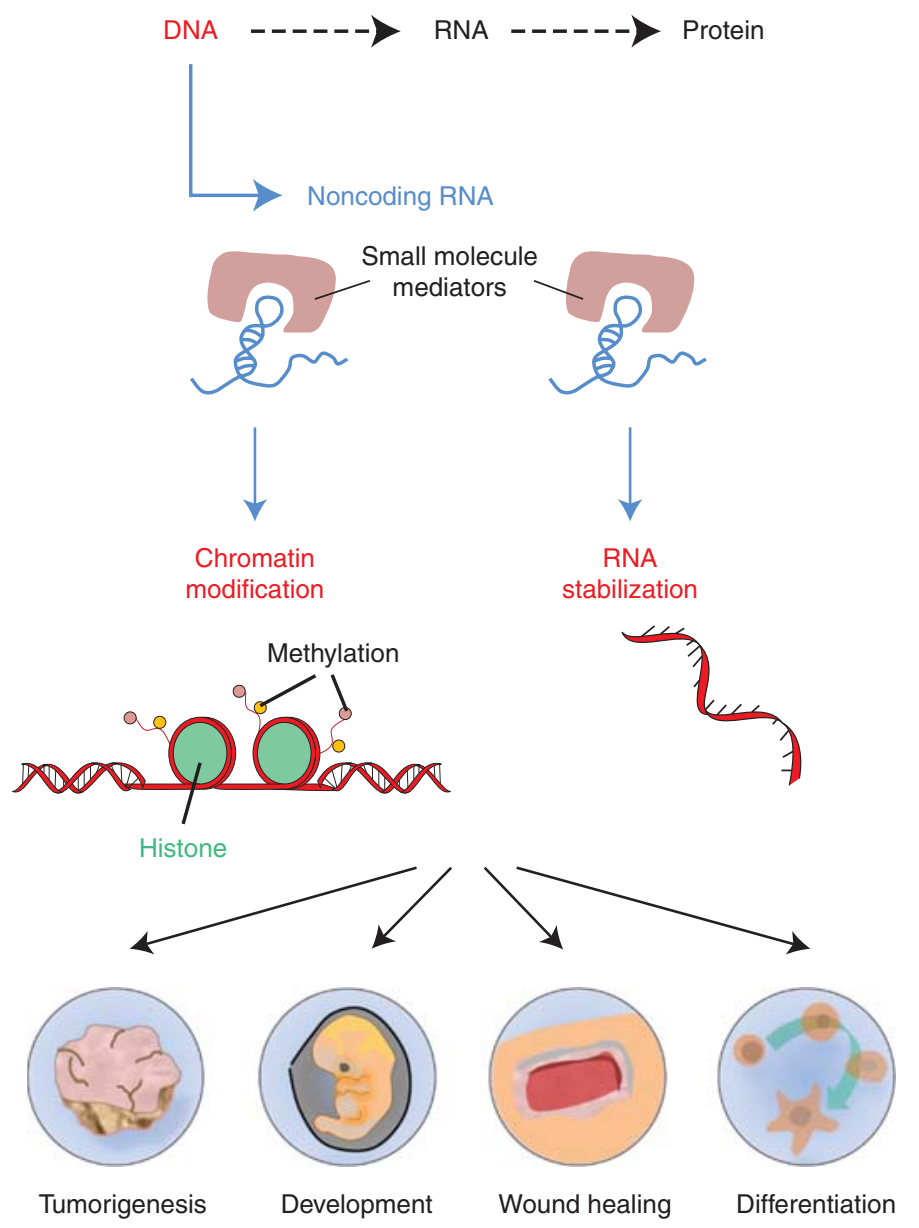

Figure 1. Functional schematic of lncRNAs. IncRNAs may function by partnering with small molecule regulators and/or mediators (such as transcription factors, chromatin modification enzymes, or DNA-binding proteins) or by stabilizing RNAs through posttranscriptional mechanisms to bring about gene expression changes via histone modifications and chromatin folding. This ultimately results in downstream regulation of disparate processes including tumorigenesis, embryonic development, wound healing, and cellular differentiation. 
netic status and transcriptional network in any given cell type, and that they provide a means to integrate external differentiation cues with dynamic nuclear responses through the regulation of a metastable epigenome. It is clear that the transmission of genetic information involves a dialog between DNA and RNA, mediated by ncRNAs; the input of these nonproteincoding RNAs is likely to be essential in shaping transcriptional and, consequently, genomic output. Moreover, interruption of RNA-mediated feedback is sure to perturb gene expression programs and bring about human disease.

What are the roles of these lncRNAs in skin biology? During the last few years, work from multiple groups has shown that epigenetic mechanisms are involved in the control of epidermal development, keratinocyte differentiation, and melanocyte functions (Millington 2008). However, many aspects of the epigenetic control of gene expression programs in skin remain to be elucidated-for example, the association of ncRNAs with functional activity of the various cutaneous cell types, the fundamental significance of these epigenetic mechanisms during skin development, differentiation, aging, and regeneration, and the still unknown complexity of multilevel regulation of gene expression programs in healthy and diseased skin are all poorly understood.

\section{CURRENT EXAMPLES OF InCRNAS WITH IMPORTANT BIOLOGICAL FUNCTIONS}

The relevance of the noncoding genome to human disease has mainly been studied in the context of widespread disruption of miRNA expression and function that is seen in human cancers (Esquela-Kerscher and Slack 2006; Hammond 2007; Croce 2009; Nicoloso et al. 2009). Recent studies, however, have begun to shed light on the manifold roles lncRNAs may play in diverse biological processes. Focusing specifically on skin, these include HOX gene regulation, development of melanoma, and epidermal differentiation (Table 1). In addition, IncRNAs have also been shown to be involved in regulating cancer metastasis and to be associated with a variety of genetic syndromes.

\section{HOTAIR Brings IncRNAs to the Forefront}

It has long been thought that HOX genes, key players in embryonic development, are regulated by cis-acting ncRNAs (Brock et al. 2009). Rinn and colleagues, in 2007, were able to systemically identify hundreds of ncRNAs transcribed from the HOX gene cluster of $11 \mathrm{hu}$ man fibroblast cell lines isolated from distinct positions along the anteroposterior and proximodistal body axes (Rinn et al. 2007). Interestingly, the ncRNAs were found to be differentially expressed in the fibroblasts according to their original position along the body axis. They further characterized one of the lncRNAs in the HOXC cluster, called HOTAIR, and made the intriguing discovery that it acts in trans to regulate another HOX gene cluster several chromosomes away. Knockdown of HOTAIR showed no changes in the HOXC cluster in which it was transcribed, but instead resulted in a loss of transcriptional repression from a $40-\mathrm{kb}$ region of the HOXD cluster (Rinn et al. 2007). In addition, the repressive mark, trimethylated histone $\mathrm{H} 3 \mathrm{~K} 27$, and the epigenetic regulatory complex that produces this mark, the polycomb complex PRC2, were no longer present at that particular region of the HOXD cluster when HOTAIR was depleted. Pull-down experiments of PRC2 components showed a direct and specific interaction with HOTAIR lncRNA (Rinn et al. 2007). These findings raise intriguing questions about how lncRNAs function and provides a glimpse of the functional complexity of this class of regulatory RNAs.

More recently, expression of HOTAIR has been associated with cancer metastasis (Gupta et al. 2010). Elevated expression of HOTAIR is observed in primary and metastatic breast cancer, accompanied by an altered chromatin state; PRC2 is recruited to almost 1000 genes that normally do not bind to PRC2 in epithelial cells, resulting in the down-regulation of multiple metastasis suppressor genes, including HOXD10. Intriguingly, the altered PRC2 occupancy profile induced by HOTAIR in breast epithelial cell resembles the PRC2 occupancy profile in distal fibroblasts in which HOTAIR is normally expressed (Gupta et al. 2010). Con- 
D.C. Wan and K.C. Wang
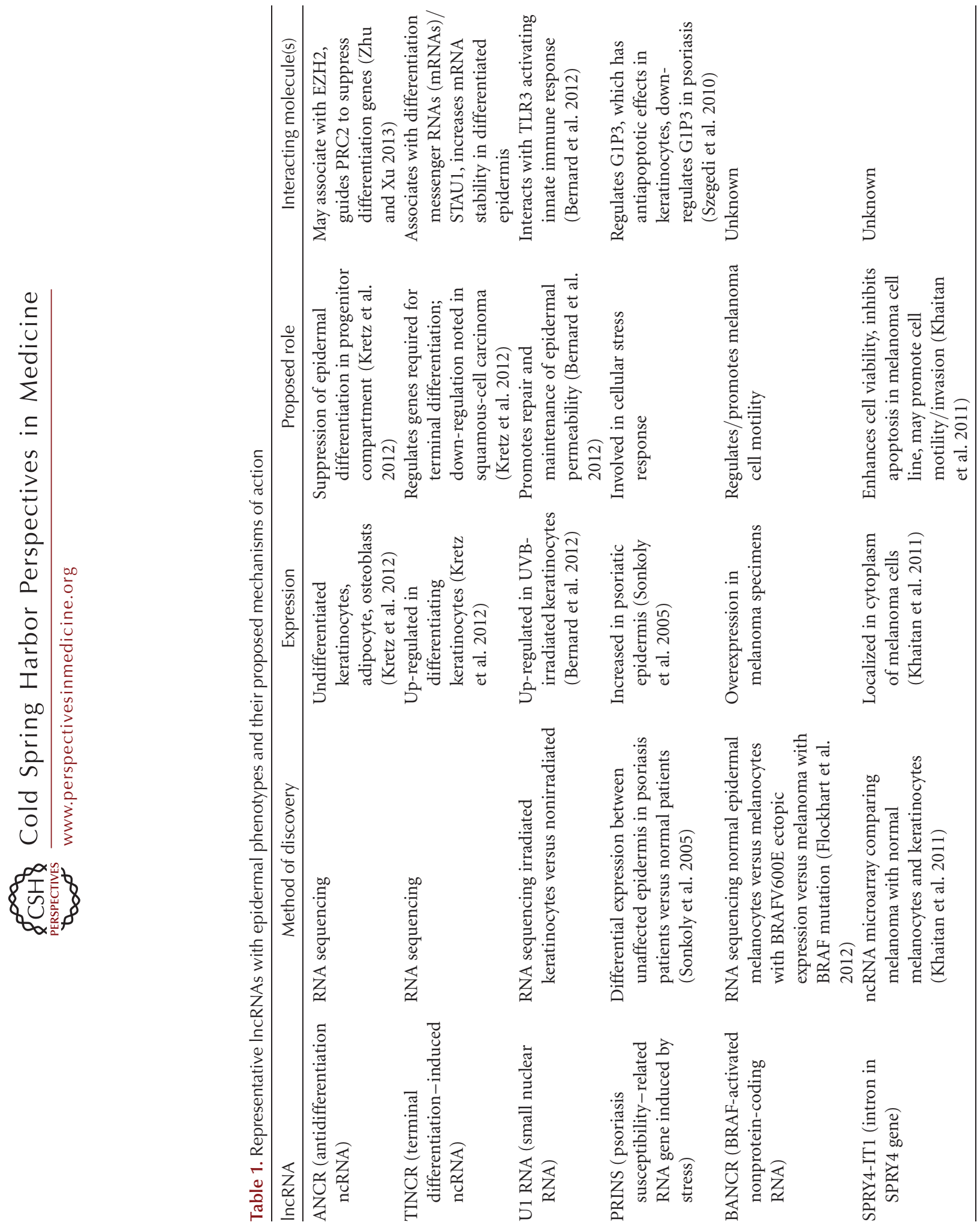
versely, depletion of HOTAIR from cancer cells led to reduced invasiveness (Gupta et al. 2010), suggesting that lncRNA-mediated targeting of PRC2 complexes may be a critical event during breast tumorigenesis. What is perhaps most interesting (and potentially more clinically significant) is the finding that not only is HOTAIR highly induced (up to 2000-fold) in metastatic breast cancer samples, high expression of HOTAIR in primary breast tumors is a powerful predictor of eventual metastasis and death, independent of known clinical/pathologic risk factors (Gupta et al. 2010). The implication of this set of findings is that lncRNAs, such as HOTAIR, can and often do alter and regulate epigenetic states in cells to affect phenotypic changes by targeting of chromatin-modifying complex occupancy/localization/enzymatic activity in trans.

\section{HOTTIP Representing Tip of the Iceberg} in Mechanisms of Locus Control

The same group that identified HOTAIR added another twist to the IncRNA story by characterizing another lncRNA from the human HoxA cluster that was appropriately named HOTTIP, for HoxA transcript at the distal tip (Wang et al. 2011). In contrast to HOTAIR, HOTTIP was shown to be important for the active expression of an entire cluster of HoxA genes in cis by serving as a key intermediate that transmits information from higher-order chromosomal looping into chromatin modifications (Wang et al. 2011). The investigators further show that HOTTIP binds specifically to WDR5, part of the histone methyltransferase MLL1 complex. Artificial tethering of HOTTIP RNA upstream of a luciferase reporter successfully boosted reporter transcription in the presence of WDR5, confirming the importance of the HOTTIP RNA itself in transcriptional activation, rather than merely the act of transcription through the HOTTIP genomic locus (Wang et al. 2011). These data suggest that HOTTIP, by virtue of its location owing to chromosomal looping, can coordinately activate the HoxA genes through recruitment of histone-modifying enzymes, a process that is reminiscent of the phenomenon termed locus control. It remains to be seen whether lncRNAs such as HOTTIP are as prevalent and significant in gene activation as their known roles in gene silencing.

\section{IncRNAs with Critical Roles in Epidermal Differentiation and Cancer}

Of specific interest to skin biologists is the explosion of progress that has been made over the past few years uncovering the widespread involvement of lncRNAs in seemingly every important process in cutaneous biology. A few such examples will be discussed in depth.

One of the prototypes of epidermal lncRNAs is ANCR, which was recently shown to maintain the epidermal progenitor state (Kretz et al. 2012), providing a glimpse into how these RNAs can act to maintain the undifferentiated state in somatic tissue progenitor cells. Using transcriptome sequencing and tiling arrays to compare lncRNA expression in human keratinocytes during calcium-induced differentiation, Kretz and colleagues (2013) identified an lncRNA that was down-regulated during epidermal differentiation; expression of the RNA was also found to be decreased in other terminally differentiated cell types including osteoblasts and adipocytes. ANCR depletion by RNA interference led to rapid differentiation gene induction in cultured keratinocytes as well as in regenerated, organotypic epidermal tissue, a model that has been used to faithfully recapitulate the histology, structure, and gene expression of human epidermis (Ridky et al. 2010). Interestingly, ANCR depletion resulted in differentiation protein expression in the epidermal basal layer from which they are normally excluded. Thus, ANCR is required to enforce the undifferentiated cell state within the epidermis. It is likely that ANCR, similar to other lncRNAs such as HOTAIR and HOTTIP, exerts its effects through binding to a protein partner. Understanding the intricate relationship between the lncRNA and its binding protein will undoubtedly uncover additional novel mechanisms in gene regulatory pathways.

In addition to ANCR, Kretz and colleagues (2013) also recently uncovered a novel lncRNA 
with significant functional impact on homeostasis and differentiation of mature epidermal tissue. Using cultured keratinocytes and highthroughput full transcriptome sequencing, they found an IncRNA, TINCR that was required for maintaining high mRNA abundance of key differentiation genes such as filaggrin, loricrin, and members of the arachidonate lipoxygenases family ALOXE3 and ALOX12B, many of which are mutated in human skin diseases. TINCRdeficient epidermis lacked terminal differentiation ultrastructures, including keratohyalin granules and intact lamellar bodies.

Surprisingly, it turns out that TINCR controls human epidermal differentiation by a posttranscriptional mechanism. Genome-scale RNA interactome analysis revealed that TINCR interacts with a suite of differentiation mRNAs and a high-throughput screen to analyze TINCRprotein binding revealed direct binding of TINCR RNA to the Staufen1 (STAU1) protein (Kretz et al. 2013). Interestingly, STAU1-deficient tissue recapitulated the impaired epidermal differentiation seen with TINCR depletion. Furthermore, the TINCR/STAU1 complex appears to mediate stabilization of differentiation mRNAs, such as keratin 80 , an important structural protein in keratinocyte epithelium. Taken together, these data point to TINCR as a key lncRNA required for epithelial differentiation through inducible lncRNA binding to differentiation mRNAs to ensure their expression. Therefore, this supports a potentially important role for lncRNAs and the proteins and mRNAs that interact with them in the control of somatic tissue differentiation.

lncRNAs have also been implicated as important players in cutaneous malignancies. By applying sequence-tagged site real-time PCRbased gene dose mapping to a French melanoma-neural system tumor syndrome family, Pasamant et al. (2007) identified a major lncRNA candidate, ANRIL (antisense noncoding RNA in the INK4 locus), located in the p15/ CDKN2B-p16/CDKN2A-p14/ARF gene cluster and associated with melanoma. The investigators found coordinated transcriptional regulation of ANRIL and p14/ARF (as well as p16/ CDKN2A and p15/CDKN2B to a lesser extent) in both normal human tissue and human breast tumors. Using an ncRNA microarray, Perera and his colleagues compared lncRNAs in several melanoma cell lines, melanocytes and keratinocyte controls, as well as in different human patient samples (Khaitan et al. 2011), and found that a number of lncRNAs are differentially expressed in melanoma cell lines in comparison to melanocytes and keratinocyte controls. One lncRNA in particular, SPRY4-IT1, was found to be elevated in melanoma cells in which it promotes cellular survival and invasion. Knockdown results in defects in cell growth, differentiation, and higher rates of apoptosis in melanoma cell lines (Khaitan et al. 2011). Thus, increased expression of lncRNAs such as SPRY4-IT1 may play an important role in the molecular underpinnings of human melanoma and perhaps can even serve as an early biomarker for its detection. The molecular mechanisms by which SPRY4-IT1 acts to affect melanoma progression and metastasis remain to be determined.

Taking advantage of next-generation sequencing technologies, Flockhart and colleagues (2012) compared the transcriptional profiles of wild-type primary human melanocytes with those carrying the BRAF (V600E) mutation and identified another candidate lncRNA involved in the migration of melanoma cells in vitro. Termed BANCR, this RNA is also highly expressed and up-regulated in primary human melanomas with the BRAF (V600E) mutation. The molecular mechanisms by which BANCR acts to affect melanoma progression and metastasis remain to be determined. Similarly, Lee and colleagues, using a genome-wide transcriptome profiling approach via RNA-sequencing in patient-matched populations of malignant versus nonmalignant $\mathrm{CD} 4^{+} \mathrm{T}$ cells, have identified a group of Sezary cell-associated transcripts (SeCATs) of yet unknown function that may be predictors of disease prognosis (Lee et al. 2012).

\section{Involvement of IncRNAs in Genetic Syndromes with Cutaneous Manifestations}

Multiple lines of evidence increasingly link mutations and dysregulation of lncRNAs to di- 
verse human diseases. Alterations in the primary structure, secondary structure, and expression levels of lncRNAs as well as their cognate RNA-binding proteins underlie diseases ranging from neurodegeneration to cancer (Wapinski and Chang 2011). A few examples include H19 and KCNQ1OT1 in Beckwith-Wiedemann syndrome, H19 in Silver-Russell syndrome, and NESP antisense in McCune-Albright syndrome (Eggermann 2009).

Beckwith-Wiedemann syndrome, a lossof-imprinting pediatric overgrowth disorder involving congenital abdominal wall defects, macroglossia, and gigantism, has been reported to have an incidence of one in approximately 14,000 births (Choufani et al. 2010). Recent studies have described aberrant expression of KCNQ1OT1, a 91-kb lncRNA localized to the nucleolus, to be involved with this syndrome (Pandey et al. 2008; Chiesa et al. 2012). KCNQ1OT1 resides in the KCNQ1 locus that contains 8-10 protein-coding genes expressed from the maternal allele along with the paternally expressed lncRNA (Kanduri 2011). Investigations have identified interactions between KCNQ1OT1 and both histone methyltransferase G9a, which dimethylates $\mathrm{H} 3 \mathrm{~K}$, and PRC2, resulting in transcriptional silencing of the KCNQ1 locus (Pandey et al. 2008). An 890-bp silencing domain on the $5^{\prime}$ end of KCNQ1OT1 has also been shown to facilitate the interaction of DNA methyltransferase 1 with chromatin, leading to changes in methylation patterns at the KvDMR1 and H19/IGF2 clusters (Lee et al. 1999; Mohammad et al. 2012; Robbins et al. 2012). Subsequent hypermethylation of the H19 promoter region has been reported to be a major cause for gigantism (Bliek et al. 2006). Collectively, such changes to the epigeneticlandscape have thus been associated with misregulation of imprinted loci and linked to the development of Beckwith-Wiedemann syndrome.

In contrast to Beckwith-Wiedemann syndrome, hypomethylation of the paternal H19 promoter region has instead been reported in a series of patients with growth retardation and asymmetric development seen in the full spectrum of Silver-Russell syndrome (Bliek et al. 2006). Classically, patients with Silver-Russell syndrome show intrauterine growth retardation, poor postnatal growth, short stature, and a triangular, asymmetric face, with long eyelashes, thin lips, and mild retrognathia (Price et al. 1999). Although our understanding of H19 continues to evolve, this $2.3-\mathrm{kb}$ lncRNA has been shown to also contain an miRNA (miR675 ) in exon one (Cai and Cullen 2007). Both sense and antisense transcripts from the H19 locus have been identified and found to bind PRC2, thereby acting at the level of transcription to regulate Igf2 (Zhao et al. 2010). Furthermore, H19 has also been shown to bind other Igf2 mRNA binding-protein family members, thereby functionally competing for Igf2 mRNA as a mechanism for posttranscriptional regulation (Runge et al. 2000). As recent studies have now begun to suggest, an association between Silver-Russell syndrome and assisted reproductive technologies such as in vitro fertilization, the specter of epimutations at paternal loci, has been raised with this process (Butler 2009; Chopra et al. 2010).

McCune-Albright syndrome, a genetic disorder with polyostotic fibrous dysplasia, endocrine hyperfunction, and unilateral café-au-lait spots, has been described to arise from a postzygotic mutation in the gene GNAS1 that prevents down-regulation of cAMP signaling (Lietman et al. 2007). The GNAS locus is a complex region containing NESP and GNASXI, proteins with unknown functions expressed in neuroendocrine tissues, along with the $\mathrm{G}$ protein $\alpha$ subunit GNAS (Wroe et al. 2000). Interestingly, strand-specific analysis has now confirmed the existence of a paternally expressed NESP antisense transcript that may play a role in regulation of the GNAS cluster (Williamson et al. 2011). NESP antisense is thought to modulate demethylation of H3K4me3 and deplete H3K36me3, resulting in repression in cis of its sense counterpart NESP (Williamson et al. 2011). Because NESP forms a single transcription unit with GNASXI and GNAS, these findings thus have potential implications for epigenetic silencing by lncRNA in the development of McCune-Albright syndrome.

With these studies highlighting the involvement of lncRNAs in Beckwith-Wiedemann, 
Silver-Russell, and McCune-Albright syndromes, it would therefore not be surprising to find additional lncRNAs that may play significant functional roles in a multitude of other pathologies. Indeed, investigations have begun to characterize various lncRNAs in the development of atherosclerosis, Alzheimer's disease, and transient neonatal diabetes (Temple 2002; Faghihi et al. 2008; Burd et al. 2010; Esteller 2011). And over the next several years, undoubtedly more lncRNAs will continue to be characterized, many of which may be disrupted in other nontumoral disorders.

\section{CONCLUSION AND MAJOR OPEN QUESTIONS}

Of course, there is also considerable interest and potential in the application of similar transcriptome interrogation approaches to the study of other types of dermatologic disorders, such as other malignant and benign neoplasms, mosaic disorders, genodermatoses, and inflammatory and even autoimmune processes. Because RNA, like DNA, is also inherently sequence-specific and transcribed in a developmentally specific manner, RNA (and by extension lncRNAs) would also be an ideal regulator of spatial and temporal specificity during both normal development and disease. For instance, the Hox lncRNA HOTTIP is transcribed in one location in the genome, at approximately fewer than one copy per cell on average (Wang et al. 2011), therefore, it is uniquely positioned to modulate specific chromatin modifiers to that location. One can certainly imagine numerous instances in which the interactions between the lncRNAs and their protein and/or nucleic acid partners in specific cell types at specific times synergize to bring about particular cutaneous phenotypes in the organism.

Another broad area of current and future exploration is that of lncRNAs as drug targets. As more lncRNAs are unraveled and their roles dissected, it is becoming increasingly evident that the involvement of these molecules in cancer is much more extensive than initially thought. Several miRNA-expression analyses in both hematological malignancies and solid tumors have shown that, aside from significant differences in expression between tumor and normal states, distinct tumor-specific miRNA signatures exist-perhaps this would be the case for lncRNAs as well. IncRNAs and the protein machineries that are involved in their biogenesis or activity are attractive targets of novel therapeutic approaches. Thus far, most work in this area is in the context of the role of miRNAs in cancer (Stenvang et al. 2008). Better characterization of the IncRNA-protein "interactome" will undoubtedly lead to new molecular insights and hereto untapped opportunities for researchers and clinicians to modulate the genome at the epigenetic level to treat conditions such as cancer. In similar fashion, dynamic expression profiles for specific miRNAs have been shown to exist at various phases of wound healing that may guide angiogenesis (Shilo et al. 2007). Parallel regulation of lncRNAs during wound regeneration would likely contribute to this process also, which may provide novel targets for the development of therapeutics aimed at the treatment of chronic nonhealing wounds. As far as the future impact and success of the various approaches are concerned, these are still in their incipient stages, but the potential is enormous.

Because of their extremely precise regulation, depending on factors like cellular state, tissue type, or disease, IncRNAs also represent a novel class of potent biomarker candidates. Additionally, because of the relative novelty of the research area and the large number of lncRNAs that are being identified on an ongoing basis, there are near-infinite combinations of mechanisms at the molecular level that offer broad therapeutic possibilities.

\section{REFERENCES}

Aravin AA, Sachidanandam R, Girard A, Fejes-Toth K, Hannon GJ. 2007. Developmentally regulated piRNA clusters implicate MILI in transposon control. Science 316: 744747.

Bernard JJ, Cowing-Zitron C, Nakatsuji T, Muehleisen B, Muto J, Borkowski AW, Martinez L, Greidinger EL, Yu BD, Gallo RL. 2012. Ultraviolet radiation damages self noncoding RNA and is detected by TLR3. Nat Med 18: $1286-1290$.

Bernstein E, Allis CD. 2005. RNA meets chromatin. Genes Dev 19: 1635-1655. 
Bliek J, Terhal P, van den Bogaard M-J, Maas S, Hamel B, Salieb-Beugelaar G, Simon M, Letteboer T, van der Smagt J, Kroes H, et al. 2006. Hypomethylation of the H19 gene causes not only Silver-Russell syndrome (SRS) but also isolated asymmetry or an SRS-like phenotype. Am J Human Genet 78: 604-614.

Bracken AP, Helin K. 2009. Polycomb group proteins: Navigators of lineage pathways led astray in cancer. Nat Rev Cancer 9: 773-784.

Brennecke J, Aravin AA, Stark A, Dus M, Kellis M, Sachidanandam R, Hannon GJ. 2007. Discrete small RNA-generating loci as master regulators of transposon activity in Drosophila. Cell 128: 1089-1103.

Brock HW, Hodgson JW, Petruk S, Mazo A. 2009. Regulatory noncoding RNAs at Hox loci. Biochem Cell Biol 87: $27-34$.

Burd CE, Jeck WR, Liu Y, Sanoff HK, Wang Z, Sharpless NE. 2010. Expression of linear and novel circular forms of an INK4/ARF-associated non-coding RNA correlates with atherosclerosis risk. PLoS Genet 6: e1001233.

Butler MG. 2009. Genomic imprinting disorders in humans: A mini-review. J Assist Reprod Genet 26: 477-486.

Cai X, Cullen BR. 2007. The imprinted H19 noncoding RNA is a primary microRNA precursor. RNA 13: $313-$ 316.

Chiesa N, De Crescenzo A, Mishra K, Perone L, Carella M, Palumbo O, Mussa A, Sparago A, Cerrato F, Russo S, et al. 2012. The KCNQ1OT1 imprinting control region and non-coding RNA: New properties derived from the study of Beckwith-Wiedemann syndrome and Silver-Russell syndrome cases. Hum Mol Genet 21: 10-25.

Chopra M, Amor DJ, Sutton L, Algar E, Mowat D. 2010. Russell-Silver syndrome due to paternal H19/IGF2 hypomethylation in a patient conceived using intracytoplasmic sperm injection. Reprod Biomed Online 20: 843-847.

Choufani S, Shuman C, Weksberg R. 2010. Beckwith-Wiedemann syndrome. Am J Med Genet 154C: 343-354.

Claverie JM. 2005. Fewer genes, more noncoding RNA. Science 309: 1529-1530.

Croce CM. 2009. Causes and consequences of microRNA dysregulation in cancer. Nat Rev Genet 10: 704-714.

Eggermann T. 2009. Silver-Russell and Beckwith-Wiedemann syndromes: Opposite (Epi)mutations in 11p15 result in opposite clinical pictures. Horm Res 71: 30-35.

Esquela-Kerscher A, Slack FJ. 2006. Oncomirs-MicroRNAs with a role in cancer. Nat Rev Cancer 6: 259-269.

Esteller M. 2011. Non-coding RNAs in human disease. Nat Rev Genet 12: 861-874.

Faghihi MA, Wahlestedt C. 2009. Regulatory roles of natural antisense transcripts. Nat Rev Mol Cell Biol 10: 637-643.

Faghihi MA, Modarresi F, Khalil AM, Wood DE, Sahagan BG, Morgan TE, Finch CE, St Laurent G, Kenny PJ, Wahlestedt C. 2008. Expression of a noncoding RNA is elevated in Alzheimer's disease and drives rapid feed-forward regulation of $\beta$-secretase. Nat Med 14: 723-730.

Flockhart RJ, Webster DE, Qu K, Mascarenhas N, Kovalski J, Kretz M, Khavari PA. 2012. BRAFV600E remodels the melanocyte transcriptome and induces BANCR to regulate melanoma cell migration. Genome Res 22: $1006-$ 1014.
Gupta RA, Shah N, Wang KC, Kim J, Horlings HM, Wong DJ, Tsai M-C, Hung T, Argani P, Rinn JL, et al. 2010. Long non-coding RNA HOTAIR reprograms chromatin state to promote cancer metastasis. Nature 464: 1071-1076.

Hammond SM. 2007. MicroRNAs as tumor suppressors. Nat Genet 39: 582-583.

He L, Hannon GJ. 2004. MicroRNAs: Small RNAs with a big role in gene regulation. Nat Rev Genet 5: 522-531.

Ho Y, Elefant F, Liebhaber SA, Cooke NE. 2006. Locus control region transcription plays an active role in long-range gene activation. Mol Cell 23: 365-375.

Kanduri C. 2011. Kcnq1ot1: A chromatin regulatory RNA. Semin Cell Dev Biol 22: 343-350.

Kapranov P, Cheng J, Dike S, Nix DA, Duttagupta R, Willingham AT, Stadler PF, Hertel J, Hackermuller J, Hofacker IL, et al. 2007. RNA maps reveal new RNA classes and a possible function for pervasive transcription. Science 316: $1484-1488$.

Khaitan D, Dinger ME, Mazar J, Crawford J, Smith MA, Mattick JS, Perera RJ. 2011. The melanoma-upregulated long noncoding RNA SPRY4-IT1 modulates apoptosis and invasion. Cancer Res 71: 3852-3862.

Kim A, Zhao H, Ifrim I, Dean A. 2007. $\beta$-globin intergenic transcription and histone acetylation dependent on an enhancer. Mol Cell Biol 27: 2980-2986.

Kretz M, Webster DE, Flockhart RJ, Lee CS, Zehnder A, Lopez-Pajares V, Qu K, Zheng GXY, Chow J, Kim GE, et al. 2012. Suppression of progenitor differentiation requires the long noncoding RNA ANCR. Genes Dev 26: 338-343.

Kretz M, Siprashvili Z, Chu C, Webster DE, Zehnder A, Qu K, Lee CS, Flockhart RJ, Groff AF, Chow J, et al. 2013. Control of somatic tissue differentiation by the long noncoding RNA TINCR. Nature 493: 231-235.

Lander ES, Linton LM, Birren B, Nusbaum C, Zody MC, Baldwin J, Devon K, Dewar K, Doyle M, FitzHugh W, et al. 2001. Initial sequencing and analysis of the human genome. Nature 409: 860-921.

Lee JT. 2009. Lessons from X-chromosome inactivation: Long ncRNA as guides and tethers to the epigenome. Genes Dev 23: 1831-1842.

Lee MP, DeBaun MR, Mitsuya K, Galonek HL, Brandenburg S, Oshimura M, Feinberg AP. 1999. Loss of imprinting of a paternally expressed transcript, with antisense orientation to KVLQT1, occurs frequently in BeckwithWiedemann syndrome and is independent of insulinlike growth factor II imprinting. Proc Natl Acad Sci 96: 5203-5208.

Lee CS, Ungewickell A, Bhaduri A, Qu K, Webster DE, Armstrong R, Weng WK, Aros CJ, Mah A, Chen RO, et al. 2012. Transcriptome sequencing in Sezary syndrome identifies Sezary cell and mycosis fungoides-associated LncRNAs and novel transcripts. Blood 120: 3288-3297.

Lietman SA, Schwindinger WF, Levine MA. 2007. Genetic and molecular aspects of McCune-Albright syndrome. Pediatr Endocrinol Rev 4: 380-385.

Mendell JT. 2005. MicroRNAs: Critical regulators of development, cellular physiology and malignancy. Cell Cycle 4: $1179-1184$. 
D.C. Wan and K.C. Wang

Mercer TR, Dinger ME, Mattick JS. 2009. Long non-coding RNAs: Insights into functions. Nat Rev Genet 10: 155159.

Millington GWM. 2008. Epigenetics and dermatological disease. Pharmacogenomics 9: 1835-1850.

Mohammad F, Pandey GK, Mondal T, Enroth S, Redrup L, Gyllensten U, Kanduri C. 2012. Long noncoding RNAmediated maintenance of DNA methylation and transcriptional gene silencing. Development 139: 2792-2803.

Nagano T, Fraser P. 2009. Emerging similarities in epigenetic gene silencing by long noncoding RNAs. Mamm Genome 20: $557-562$.

Nicoloso MS, Spizzo R, Shimizu M, Rossi S, Calin GA. 2009. MicroRNAs-The micro steering wheel of tumour metastases. Nat Rev Cancer 9: 293-302.

Ørom UA, Derrien T, Beringer M, Gumireddy K, Gardini A, Bussotti G, Lai F, Zytnicki M, Notredame C, Huang Q, et al. 2010a. Long noncoding RNAs with enhancer-like function in human cells. Cell 143: 46-58.

Ørom UA, Derrien T, Guigo R, Shiekhattar R. 2010b. Long noncoding RNAs as enhancers of gene expression. Cold Spring Harbor Symposia on Quantitative Biology 75: 325331.

Pandey RR, Mondal T, Mohammad F, Enroth S, Redrup L, Komorowski J, Nagano T, Mancini-Dinardo D, Kanduri C. 2008. Kcnqlotl antisense noncoding RNA mediates lineage-specific transcriptional silencing through chromatin-level regulation. Mol Cell 32: 232-246.

Pasmant E, Laurendeau I, Héron D, Vidaud M, Vidaud D, Bièche I. 2007. Characterization of a germ-line deletion, including the entire INK4/ARF locus, in a melanomaneural system tumor family: Identification of ANRIL, an antisense noncoding RNA whose expression coclusters with ARF. Cancer Res 67: 3963-3969.

Price SM, Stanhope R, Garrett C, Preece MA, Trembath RC. 1999. The spectrum of Silver-Russell syndrome: A clinical and molecular genetic study and new diagnostic criteria. J Med Genet 36: 837-842.

Ridky TW, Chow JM, Wong DJ, Khavari PA. 2010. Invasive three-dimensional organotypic neoplasia from multiple normal human epithelia. Nat Med 16: 1450-1455.

Rinn JL, Kertesz M, Wang JK, Squazzo SL, Xu X, Brugmann SA, Goodnough LH, Helms JA, Farnham PJ, Segal E, et al 2007. Functional demarcation of active and silent chromatin domains in human HOX loci by noncoding RNAs. Cell 129: 1311-1323.

Robbins KM, Chen Z, Wells KD. 2012. Expression of KCNQ1OT1, CDKN1C, H19, and PLAGL1 and the methylation patterns at the KvDMR1 and H19/IGF2 imprinting control regions is conserved between human and bovine. J Biomed Sci 19: 95.

Runge S, Nielsen FC, Nielsen J, Lykke-Andersen J, Wewer UM, Christiansen J. 2000. H19 RNA binds four molecules of insulin-like growth factor II mRNA-binding protein. J Biol Chem 275: 29562-29569.
Shilo S, Roy S, Khanna S, Sen CK. 2007. MicroRNA in cutaneous wound healing: A new paradigm. DNA Cell Biol 26: $227-237$.

Sonkoly E, Bata-Csorgo Z, Pivarcsi A, Polyanka H, Kenderessy-Szabo A, Molnar G, Szentpali K, Bari L, Megyeri K, Mandi Y, et al. 2005. Identification and characterization of a novel, psoriasis susceptibility-related noncoding RNA gene, PRINS. J Biol Chem 280: 24159-24167.

Stenvang J, Lindow M, Kauppinen S. 2008. Targeting of microRNAs for therapeutics. Biochem Soc Trans 36: 1197-1200.

Szegedi K, Sonkoly E, Nagy N, Nemeth IB, Bata-Csorgo Z, Kemeny L, Dobozy A, Szell M. 2010. The antiapoptotic protein G1P3 is overexpressed in psoriasis and regulated by the noncoding RNA, PRINS. Exp Dermatol 19: $269-278$.

Temple IK. 2002. Transient neonatal diabetes, a disorder of imprinting. J Med Genet 39: 872-875.

Venter J, Adams M, Myers E, Li P, Mural R, Sutton GG, Smith HO, Yandell M, Evans CA, Holt RA, et al. 2001. The sequence of the human genome. Science 291: $1304-$ 1351.

Wang KC, Chang HY. 2011. Molecular mechanisms of long noncoding RNAs. Mol Cell 43: 904-914.

Wang KC, Yang YW, Liu B, Sanyal A, Corces-Zimmerman R, Chen Y, Lajoie BR, Protacio A, Flynn RA, Gupta RA, et al. 2011. A long noncoding RNA maintains active chromatin to coordinate homeotic gene expression. Nature 472: $120-124$

Wapinski O, Chang HY. 2011. Long noncoding RNAs and human disease. Trends Cell Biol 21: 354-361.

Whitehead J, Pandey GK, Kanduri C. 2009. Regulation of the mammalian epigenome by long noncoding RNAs. Biochim Biophys Acta 1790: 936-947.

Williamson CM, Ball ST, Dawson C, Mehta S, Beechey CV, Fray M, Teboul L, Dear TN, Kelsey G, Peters J. 2011. Uncoupling antisense-mediated silencing and DNA methylation in the imprinted Gnas cluster. PLoS Genet 7: e1001347.

Wilusz JE, Sunwoo H, Spector DL. 2009. Long noncoding RNAs: Functional surprises from the RNA world. Genes Dev 23: 1494-1504.

Wroe SF, Kelsey G, Skinner JA, Bodle D, Ball ST, Beechey CV, Peters J, Williamson CM. 2000. An imprinted transcript, antisense to Nesp, adds complexity to the cluster of imprinted genes at the mouse Gnas locus. Proc Natl Acad Sci 97: 3342-3346.

Zhao J, Ohsumi TK, Kung JT, Ogawa Y, Grau DJ, Sarma K, Song JJ, Kingston RE, Borowsky M, Lee JT. 2010. Genome-wide identification of polycomb-associated RNAs by RIP-seq. Mol Cell 40: 939-953.

Zhu L, Xu P-C. 2013. Downregulated LncRNA-ANCR promotes osteoblast differentiation by targeting EZH2 and regulating Runx2 expression. Biochem Biophys Res Commun 432: 612-617. 


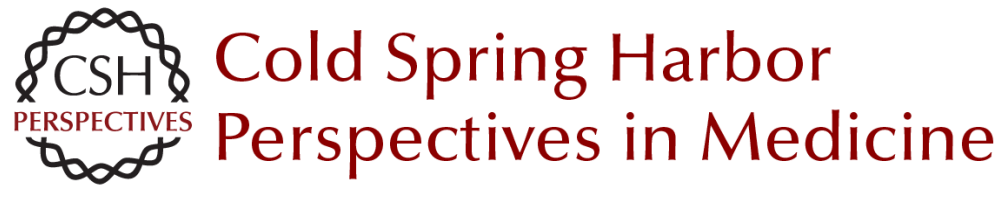

\section{Long Noncoding RNA: Significance and Potential in Skin Biology}

Derrick C. Wan and Kevin C. Wang

Cold Spring Harb Perspect Med 2014; doi: 10.1101/cshperspect.a015404

Subject Collection The Skin and Its Diseases

Melanoma: Clinical Features and Genomic Insights

Elena B. Hawryluk and Hensin Tsao

Wound Healing and Skin Regeneration

Makoto Takeo, Wendy Lee and Mayumi Ito

The Dermal Papilla: An Instructive Niche for

Epithelial Stem and Progenitor Cells in

Development and Regeneration of the Hair Follicle Bruce A. Morgan

Immunology and Skin in Health and Disease Jillian M. Richmond and John E. Harris

Desmosomes: Regulators of Cellular Signaling and Adhesion in Epidermal Health and Disease Jodi L. Johnson, Nicole A. Najor and Kathleen J. Green

Markers of Epidermal Stem Cell Subpopulations in Adult Mammalian Skin Kai Kretzschmar and Fiona M. Watt

Psoriasis Paola Di Meglio, Federica Villanova and Frank O. Nestle

Cell Therapy in Dermatology Gabriela Petrof, Alya Abdul-Wahab and John A. McGrath
Modeling Cutaneous Squamous Carcinoma

Development in the Mouse

Phillips Y. Huang and Allan Balmain

Natural and Sun-Induced Aging of Human Skin Laure Rittié and Gary J. Fisher

Advanced Treatment for Basal Cell Carcinomas Scott X. Atwood, Ramon J. Whitson and Anthony E. Oro

Epidermal Polarity Genes in Health and Disease Frederik Tellkamp, Susanne Vorhagen and Carien M. Niessen

Induced Pluripotent Stem Cells in Dermatology:

Potentials, Advances, and Limitations Ganna Bilousova and Dennis R. Roop

The Genetics of Human Skin Disease Gina M. DeStefano and Angela M. Christiano

p53/p63/p73 in the Epidermis in Health and Disease

Vladimir A. Botchkarev and Elsa R. Flores

Diversification and Specialization of Touch

Receptors in Skin

David M. Owens and Ellen A. Lumpkin

For additional articles in this collection, see http://perspectivesinmedicine.cshlp.org/cgi/collection/ 